\title{
Interdisciplinaridade e o desafio da leishmaniose visceral
}

\author{
Interdisciplinarity and the challenge of visceral leishmaniasis
}

\section{Carlos Graeff-Teixeira}

Professor Titular de Parasitologia da Faculdade de Biociências. Coordenador do Laboratório de Parasitologia Molecular do Instituto de Pesquisas Biomédicas. Coordenador do Setor de Pesquisa Interdisciplinar da Pró-Reitoria de Pesquisa e Inovação (PROPESQ), Pontifícia Universidade Católica do Rio Grande do Sul.

DESCRITORES: LEISHMANIOSE VISCERAL/epidemiologia; ZOONOSES; COMUNICAÇÃO INTERDISCIPLINAR.

KEY WORDS: LEISHMANIASIS, VISCERAL/epidemiology; ZOONOSES; INTERDISCIPLINARY COMMUNICATION.

A formação em Medicina Tropical tem um dos seus centros mais importantes do mundo no Rio de Janeiro: o centenário Instituto Oswaldo Cruz. Inicialmente Instituto Soroterápico de Manguinhos, posteriormente torna-se o que é atualmente a Fundação Oswaldo Cruz (FIOCRUZ), com unidades espalhadas por várias cidades brasileiras, desde Manaus até Curitiba. Uma característica da FIOCRUZ é a diversidade das disciplinas que se reúnem na busca de soluções para a saúde da população: além de estudos biomédicos e desenvolvimento tecnológico, a saúde pública, a ecologia, a história, a antropologia, a popularização da ciência, entre tantos outros enfoques especializados.

Aqueles que fizeram pós-graduação nessa instituição na década de 1980 puderam eventualmente ter contato com alguns dos maiores expoentes na pesquisa biomédica. Um deles foi o professor Leônidas de Mello Deane (Figura 1). Ele fez enormes contribuições científicas sobre a biologia do parasitismo e dos seus vetores, a epidemiologia da infecção humana e os reservatórios silvestres das leishmanioses. Em uma de suas aulas, recheadas de inúmeras histórias de aventuras nos penosos trabalhos de campo nos sertões, ele embargou a voz e deixou escorrer algumas lágrimas. Explicou emocionado: não entendia por que, com tudo que já se sabia (para o que ele próprio tinha dedicado tanto esforço), ainda não se podia controlar o calazar, um nome popular da leishmaniose

Correspondência para / Correspondence to:

CARLOS GRAEFF-TEIXEIRA

Faculdade de Biociências da PUCRS - Departamento de Ciências Microbiológicas

Av. Ipiranga, 6681, Prédio 12 C, Sala 282

90619-900 - Porto Alegre, RS - Brasil

Telefone: (51) 3320-3000

E-mail: graeteix@pucrs.br visceral. Aquelas lágrimas foram a expressão de um paradoxo: a convivência da crença no reducionismo, base da ciência como a conhecemos nos últimos dois séculos, com a consciência e a experiência do professor Deane no trabalho integrado de vários saberes para a investigação da leishmaniose.

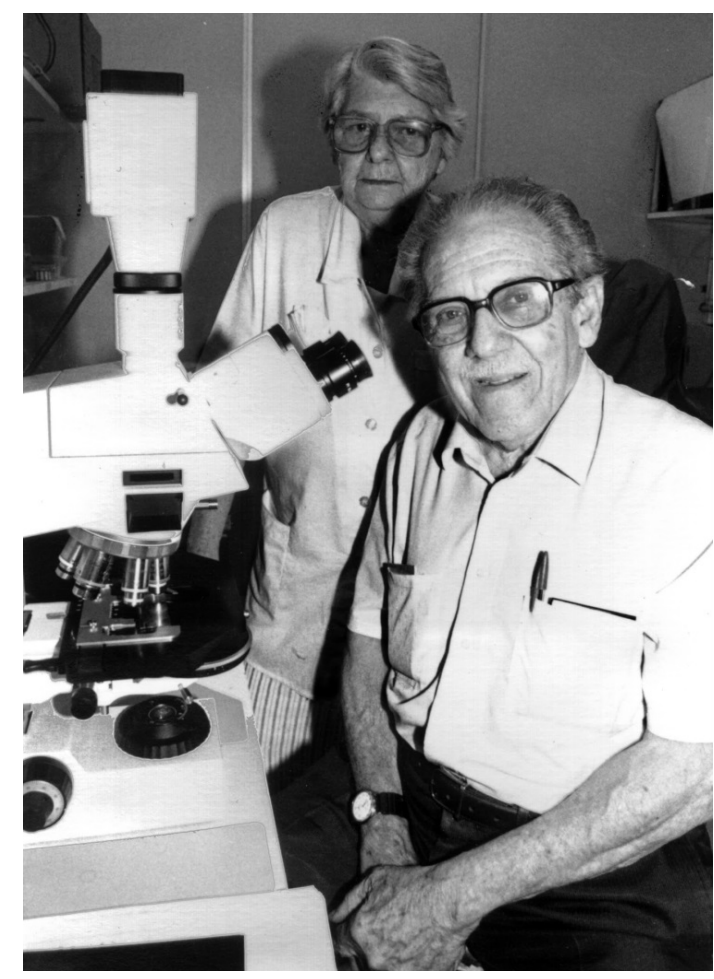

Figura 1. Professor Leônidas de Mello Deane ao microscópio, com sua companheira da vida inteira, a também eminente protozoologista Maria José Von Paumgartten Deane. (Fonte: acervo fotográfico da Fundação Oswaldo Cruz - FIOCRUZ). 
O artigo de Barbosa e Costa, ${ }^{1}$ publicado nesta edição, demonstra que a leishmaniose persiste infectando e matando. Um dos dados interessantes deste estudo é a confirmação da tendência à urbanização, que ocorre atualmente não só com a leishmaniose visceral, mas com todas as endemias antigamente definidas como "rurais". Quando que poderia se pensar que haveria um dia um foco de transmissão desta protozoose numa cidade da fronteira do Rio Grande do Sul? Lembro de uma reunião sobre discussão de currículo da Faculdade de Medicina no início dos anos 1990, quando alguém perguntou por que os alunos tinham que estudar malária, se ela não existia no Rio Grande do Sul. Nem malária, nem leishmanioses. O calazar chegou a São Borja, sem que saibamos o potencial de sua expansão no limite sul do país. ${ }^{2} \mathrm{O}$ calazar desafia e revela nossa ignorância. Ao mesmo tempo, esta crise traz uma oportunidade: a de compreender que os fenômenos complexos, como os da interação entre os protozoários (assim como vírus, vermes, artrópodes, fungos) e os seus hospedeiros, precisam de uma abordagem integrada de vários conhecimentos para gerar soluções satisfatórias. Eu diria que não há doença que não exija a interdisciplinaridade como o próximo estágio de avanço na busca de soluções. O que acontece é que a nossa cegueira não nos deixa ver que os fenômenos complexos abundam ao nosso redor. E algumas intervenções que produzem efeito satisfatório ou temporário, reforçam nossa crença de que tudo seria da mesma forma resolvido.
Barbosa e Costa analisam a epidemiologia do calazar entre jovens e referem corretamente a associação da sua gravidade com a desnutrição, de onde logo se verifica que precisamos, além de vacinas, de conhecimentos sobre determinantes sociais, antropológicos e culturais das doenças. E todos trabalhando juntos, em uma mesma equipe. A filosofia e a ética podem nos ajudar a rever a inadequação de propor a vacinação como medida isolada e considerar cumprida a missão "biomédica", enquanto as pessoas continuam mergulhadas na subcondição de vida. A bioética pode nos ajudar a reformar a visão de "especiecismo", ou "especismo", onde o homem se coloca como superior e dominante perante todos os outros seres (uma derivação do "racismo", proposta por Peter Singer ${ }^{3}$ ), para uma visão mais ecológica, onde Homo sapiens é uma dentre todas as outras espécies. Senão, vamos continuar a nos surpreender com o que um artrópode minúsculo e um protozoário intracelular conseguem fazer.

\section{REFERÊNCIAS}

1. Barbosa IR, Costa ICC. Aspectos clínicos e epidemiológicos da leishmaniose visceral em menores de 15 anos no estado do Rio Grande do Norte, Brasil. Sci Med. 2013;23(1):5-11.

2. Souza GD, Santos Ed, Andrade Filho JD. The first report of the main vector of visceral leishmaniasis in America, Lutzomyia longipalpis (Lutz \& Neiva) (Diptera: Psychodidae: Phlebotominae), in the state of Rio Grande do Sul, Brazil. Mem Inst Oswaldo Cruz. 2009;104:1181-2.

3. Edmonds D, Warburton N. Peter Singer on animals. In: (Eds.). Philosophy bites. Oxford: Oxford University Press; 2010. Cap. 3, p. 18-22. 